\title{
RBEP
}

\section{A reflexão e a ação vistas a partir de práticas psicoeducativas em pesquisas interventivas}

Simone Dalla Barba Walckoff

Heloisa Szymanski

\section{Resumo}

Este estudo investigou três práticas psicoeducativas elaboradas e utilizadas em pesquisas interventivas realizadas em uma mesma comunidade pelo Grupo de Pesquisa em Práticas Educativas e Atenção Psicoeducacional à Família, Escola e Comunidade (Ecofam), do Programa de Pós-Graduação em Psicologia da Educação da PUC-SP. Realizaram-se leituras dos relatos dos procedimentos utilizados durante o período de 2004 a 2006, buscando compreender como as práticas se apresentavam e quais as consequências da sua aplicação para os que dela participaram, tendo como pano de fundo a interrogação a respeito da possibilidade de convocação para a ação à luz do pensamento de Hannah Arendt. A análise dos relatos e as reflexões trazidas por Hannah Arendt sugerem a necessidade de uma relativização do pensamento concernente ao fim último das intervenções realizadas na comunidade, qual seja a ação, compreendida, segundo Arendt, como a iniciação de um novo movimento.

Palavras-chave: ação; reflexão; pesquisa interventiva. 


\section{Abstract \\ The reflection and the action seen through psychoeducational practices in interventive researches}

This study investigated three psychoeducational practices which were developed and utilized in an interventionist research work conducted in a community by PUC-SP's Ecofam (Research Team in Educational Practice and Psychoeducational Attention to Families, Schools and Communities, Postgraduate Programme in Educational Psychology, Catholic University of Sao Paulo). The author carried out an analysis of the procedures adopted between 2004 and 2006. Her aim was to understand how the psychoeducational practices were put into effect and what contributions they made to their participants. This was done in the light of their ability to prompt action, as seen in terms of Hannah Arendt's work. The analysis was based on hermeneutics and on the ideas proposed by Arendt. It suggests that there is a need to relativise thought in what concerns the aim of an intervention in a community, this aim being, according to Arendt, the beginning of a new movement.

Keywords: action; reflection; research intervention.

Este artigo tem como intuito ponderar sobre a relação entre pensamento e ação. ${ }^{1}$ Para tanto, partiremos de um estudo feito pelo Grupo de Pesquisa em Práticas Educativas e Atenção Psicoeducacional à Família, Escola e Comunidade (Ecofam), ligado ao programa de Pós Graduação da Educação: Psicologia da Educação da PUC-SP, a respeito das práticas psicoeducativas desenvolvidas e utilizadas pelo grupo durante 16 anos de pesquisas interventivas em uma comunidade da periferia de São Paulo (Calil, 2009).

O caráter interventivo dos estudos realizados pelo grupo Ecofam (2004) na referida comunidade pressupõe primeiramente a compreensão de que não existe neutralidade em nenhum momento de uma investigação. Em segundo lugar, conforme Szymanski e Cury (2004), que um ponto fundante da pesquisa interventiva é o ato de oferecer serviços, psicoeducativos no caso do grupo Ecofam (2004), constituídos a partir da demanda da população envolvida. Desse modo,

Por se tratar de demanda do grupo, a intervenção tem, para este, na maior parte das vezes, o sentido de prestação de serviço em psicologia. O sentido de investigação científica se constitui quando o trabalho é oferecido por pesquisadores engajados em projetos de uma instituição de pesquisa (Szymanski; Cury, 2004, p. 11).
${ }^{1}$ Ação aqui compreendida como o início de um novo movimento, portanto como mudança. 
A pesquisa realizada por Calil (2009) foi motivada pelo questionamento sobre as condições que as práticas psicoeducativas proporcionavam para possibilitar mudanças naqueles que dela participavam, tanto como serviços oferecidos para a comunidade quanto como procedimentos de pesquisa. Tinha, assim, como objetivo principal a análise das práticas desenvolvidas e sua implicação com a ação das pessoas que delas participavam. A autora que iluminou essa investigação foi Hannah Arendt.

Concentrar-nos-emos aqui em uma breve apresentação das práticas, para que possamos discutir suas bases e suas implicações com mais profundidade e abordar o aspecto principal a que este artigo se propõe: refletir a respeito da relação entre a reflexão e a ação à luz do pensamento arendtiano e suas implicações para os que trabalham na área da educação.

Como já foi mencionado anteriormente, as práticas psicoeducativas realizadas pelo Grupo Ecofam resultaram de um processo que buscava responder às demandas, tanto de pesquisadores quanto de participantes, desveladas na relação estabelecida entre o grupo de pesquisa e as pessoas da comunidade. São elas: a Entrevista Reflexiva, os Encontros Reflexivos e o Plantão Psicoeducativo.

Tais práticas têm como eixo a reflexão e o diálogo, reflexão aqui entendida como "espelhar, revelar, pensar" (Cunha, 1986, p. 670). Estes sentidos da reflexão estão intimamente vinculados ao diálogo, que permite o aparecimento de diferentes perspectivas a respeito do mundo, na medida em que os participantes das práticas, ao ouvirem uns aos outros e a si mesmos, podem vislumbrar diferentes modos de ver o mundo. Portanto, as práticas se apresentam aos participantes como uma oportunidade de rever, alterar, ampliar ou confirmar suas compreensões a respeito dos temas levantados sobre o ato de educar.

O aspecto psicológico das práticas psicoeducativas se refere à possibilidade oferecida pelo diálogo e pela reflexão de as pessoas, ao se debruçarem sobre seus diferentes modos de educar, se depararem também com diferentes possibilidades de ser, de viver. Deste modo, as intervenções realizadas podem propiciar para os que delas participam uma maior consciência de si.

O estudo mencionado teve como base de investigação os relatos das práticas psicoeducativas contidos nas teses, dissertações e relatórios de pesquisa realizados pelo grupo Ecofam na comunidade nos anos de 2004 a 2006. Após a seleção dos relatos feitos nesse período, chegamos a um número de oito pesquisas, sendo que três trabalharam com as Entrevistas Reflexivas: Cunha (2005), Vianna (2006), Fuser (2005); três utilizaram os Plantões Psicoeducativos: Melo (2004), Tinti (2006), Sanches (2006); e duas usaram como procedimento os Encontros Reflexivos: (Calil, 2004), Szymanski (2004a).

Foi feita, então, uma primeira leitura de todas as pesquisas selecionadas. Após essas leituras, foram realizadas várias outras com a atenção direcionada especificamente aos relatos das práticas. Esse caminho teve como base a hermenêutica. Como lembra Hermann (2002), a palavra hermenêutica deriva de Hermes, o mensageiro dos deuses gregos, 
que é responsável por levar e trazer mensagens de lugares distantes, desvelando, trazendo o oculto, o que está longe. A autora lembra que a hermenêutica remete também à interpretação de textos bíblicos, às jurisprudências e à filosofia clássica. Novamente, nesse caso, há uma busca de aproximação de lugares distantes, o mundo do autor e o mundo do leitor.

Podemos observar que, em ambas as origens, "é preciso dar-se conta de que há uma distância a superar" (Hermann, 2002, p. 21), apontando para uma aproximação que se origina de um diálogo entre dois mundos. Nessa relação horizontal, o conhecimento não está posto em nenhum dos lados; no caso desta pesquisa, nem nos relatos, nem na pesquisadora. A compreensão se dá ao longo dessa conversa estabelecida durante a leitura. Como lembra Hermann (2002, p. 95), "desse processo surge um conhecimento que até então não se encontrava disponível para nenhum dos envolvidos. Novas explicações de sentido surgem, dando rumo à própria compreensão".

Assim, a leitura das pesquisas foi feita na direção desse diálogo com o texto. As percepções apreendidas ao longo desse diálogo eram anotadas e, aos poucos, foram sendo agrupadas àquelas que apresentavam questões em comum, formando o que chamamos aqui de "unidades de significados" (Szymanski, 2004a p. 82). Esses agrupamentos foram se constituindo em "constelações" (Szymanski, 2004a, p. 2), que seriam traduções das questões que foram se desenhando nas unidades de significados. A respeito do processo de constituição das constelações, a autora lembra:

[...] podemos dizer que é importante refletirmos sobre onde estamos nesse vasto universo de possibilidades de interpretações. Assim como um céu pode ser desenhado de mil maneiras, assim os fenômenos. É o que a epoché nos ensina. É preciso saber em que lugar nos encontramos, de que lugar falamos, pois nossa compreensão é circunstancial, é situada (Szymanski, 2004a, p. 2). (Grifo da autora).

Ao longo das leituras dos relatos, foram se constituindo as seguintes constelações: "os sentidos do convite à reflexão", "os limites da reflexão", "a questão da condição" e "apontamentos para possibilidades de trabalho". Foram se delineando primeiramente dentro de cada uma das três práticas psicoeducativas e, após esse momento, também conjuntamente. Essa ordem será seguida em sua apresentação e discussão.

A primeira constelação que se apresentou durante as leituras foi "os sentidos do convite à reflexão". Em um primeiro momento, essa constelação aparece na entrevista reflexiva, trazida por meio das experiências de Cunha (2005), Vianna (2006) e Fuser (2005).

Nesses estudos, a reflexão buscava a elucidação de um tema específico, no caso, a questão do tempo para as professoras da escola, das drogas para os jovens entrevistados e do sentido das aulas de arte para seus alunos. Esse caminho foi proposto pelos pesquisadores e aceito pelos participantes. Nesses estudos, o fim último era a aclaração do tema, tanto por parte do pesquisador quanto dos entrevistados. 
Já no plantão psicoeducativo e nos encontros reflexivos, o convite para a reflexão se direcionava à compreensão da questão com vistas à ação. A compreensão da questão, por exemplo, do descontrole do filho (Melo, 2004), do sofrimento da filha (Tinti, 2006), das implicações da vida na criminalidade (Sanches, 2006), dos modos de habitar a cooperativa (Calil, 2004) e de educar os filhos (Szymanski, 2004a), tinha o sentido de compreensão com vistas à ação imediata (com o filho, com a filha, com o crime, na cooperativa, entre outros).

Outro dado que avigora esse sentido é que o convite à busca pela compreensão para a resolução dos problemas foi feito pelas pessoas que procuraram o plantão ou pelos grupos que participaram dos encontros reflexivos, o qual foi aceito pelos pesquisadores. Havia uma necessidade imediata de compreensão para o retorno à vida e à resolução das questões cotidianas, diferente da proposta nas pesquisas de Cunha (2005), Vianna (2006) e Fuser (2005), em que a preocupação com o tema veio, a princípio, do pesquisador e o tema foi explorado sem que houvesse nenhuma urgência para a ação imediata na realidade.

Antes de seguir adiante, é importante demarcar algumas diferenças que podem contribuir para o exame dessa constelação. Hannah Arendt (2002), ao tratar a questão do pensamento (que aqui chamamos de reflexão), faz diferenciações entre a intuição, a cognição, o pensamento filosófico ou contemplativo e a compreensão. Concentraremo-nos mais longamente nas duas últimas distinções. Todos eles têm início com o Espanto. O espanto "é um pathos, algo sofrido e não produzido". É a perplexidade que nos atinge diante de algo que até então era familiar, é um estranhamento das coisas que força o homem a voltar-se para ela (Arendt, 2002, p. 109). A intuição seria essa indicação da existência de algo que nos espanta, mas que ainda não temos condições de traduzir.

A cognição busca produzir conhecimentos cada vez mais corretos acerca do que aparece, procurando desvendar o que está oculto e corrigir possíveis ilusões dos sentidos. Segundo Arendt (2002), "em outras palavras, o intelecto (verstand) deseja apreender o que é dado aos sentidos", produzindo um conhecimento cada vez mais apurado, "livre" de ilusões, para poder aplicá-lo da forma mais controlada possível (Arendt, 2002, p. 43).

Assim, a cognição se utiliza da atividade do pensar para produzir conhecimento acerca das coisas do mundo; porém, ela não é o pensamento. Existe assim uma "distinção entre o conhecimento que usa o pensamento como meio para um fim e o pensamento propriamente dito" (Arendt, 2002, p. 50). Como lembra a autora, ao analisar a diferenciação feita por Kant entre razão e intelecto:

[...] a razão, a capacidade especulativa do homem, transcende necessariamente as faculdades cognitivas de seu intelecto: somente o que aparece e, no modo do parece-me, é dado à experiência, pode ser conhecido; mas os pensamentos também "são", e algumas coisaspensamento, a que Kant chama "ideias", embora nunca dadas à experiência e portanto incognoscíveis, tais como Deus, a liberdade e a 
mortalidade, são para nós, no sentido enfático de que a razão não pode se impedir de pensá-las e que elas são de grande interesse para os homens e para a vida do espírito. (Arendt, 2002, p. 33). (Grifos do autor).

Portanto, o pensamento não se reduz à atividade que busca produzir conhecimento, embora possa fazer parte dela. Para Arendt (2002, p. 131), ele é o "ato de descongelar" compreensões acerca do mundo, colocando em questão conceitos, valores e doutrinas constituídos pelo senso comum. Tal ato não produz outras verdades gerais que, a partir de então, serão utilizadas ou aprimoradas; pelo contrário, o pensamento é destrutivo no sentido de que devasta verdades, põe-nas em questão, sem que busque com isso estabelecer substitutos, perseguindo apenas o sentido (Arendt, 2002, p. 69). Ainda conforme a autora,

[...] isto implica que o pensamento tem sempre que começar de novo; é uma atividade que acompanha a vida e tem a ver com os conceitos como justiça, felicidade e virtude, que nos são oferecidos pela própria linguagem, expressando o significado de tudo que acontece na vida e nos ocorre enquanto estamos vivos. (Arendt, 2002, p. 134). (Grifos nossos).

Nesse processo, o descongelamento pode abrir novas perspectivas de olhar o fenômeno eternamente. A exigência da interrupção do pensamento para as resoluções de urgência da vida cotidiana é feita, digamos, a contragosto do pensamento. Esse modo de pensar é chamado por Arendt (2002) de pensamento contemplativo ou filosófico.

O modo de pensar que encontramos por parte dos pesquisadores na entrevista reflexiva, embora não se caracterize como pensamento filosófico, compartilha com este o direcionamento ao descongelamento. Nesse modo de procedimento, não há outra preocupação a não ser o desvelamento do fenômeno e a busca de seus sentidos. Também a sua interrupção não se deve ao fato de que se chegou às verdades últimas dos fenômenos e não há mais nada a interrogar, mas poderá acontecer por simples exigência da vida, como os prazos de entrega das investigações ou a disponibilidade dos participantes.

Já a compreensão busca pensar o mundo com vistas a voltar a ele, para poder habitá-lo novamente, isso porque o convite à compreensão ocorre sempre quando o mundo, antes familiar, apresenta algo novo que rompe com a ordem anterior. A preocupação do pensamento tem aqui o sentido de reconciliação com o mundo. Segundo Arendt (2001b, p. 250),

Se a essência de toda a ação, e em particular da ação política, é fazer um novo começo, então a compreensão transforma-se no outro lado da ação, sobretudo quando é essa forma de conhecimento, distinta de muitas outras, através da qual os homens que agem (e não os que se cometem com a contemplação de um processo histórico catastrófico ou salvífico) acabam por ser capazes de reconhecer aquilo que aconteceu de irredutível e de se reconciliar com o que existe de inevitável.

Dessa forma, podemos verificar uma estreita relação entre ação e compreensão. O convite à compreensão é feito aos homens de ação em 
sua lida com o mundo. Retornando às práticas psicoeducativas, podemos identificar essa reflexão que busca a compreensão, em especial nas pessoas que procuraram o plantão e os encontros reflexivos. É possível constatar por meio das histórias contadas que foi uma questão na vida, que convocava as pessoas para a reflexão, buscando assim poder voltar a ela.

É fundamental dizer que essa separação tem, digamos, uma função didática. Ou seja, não significa que nas entrevistas reflexivas não tenha havido compreensão e que nos plantões e encontros reflexivos o pensamento de cunho filosófico ou até mesmo a cognição não tenham se apresentado. Apenas estamos demarcando para qual sentido ou qual sentido marcava mais fortemente essas práticas nos relatos.

Assim, podemos encontrar inúmeros "descongelamentos" proporcionados ao longo do processo pela busca da reflexão acerca de um fenômeno. Esses ocorreram a todo o momento, de ambos os lados, tanto do pesquisador como do participante, oferecendo abertura de percepção em todas as práticas. Portanto, em todas as práticas psicoeducativas a reflexão cumpre o seu papel de abertura, mas esta se encaminha para lugares diferentes, em algumas para o aclaramento de fenômenos, em outras para a reconciliação com o mundo com vistas a lidar com ele.

Entretanto, as leituras das práticas demonstraram também que, em alguns momentos, a reflexão, apesar de possibilitar importantes aberturas, não foi suficiente para iniciar novos movimentos, para tirar os participantes da mesmidade que eles traziam como a causadora de sofrimentos. Podemos citar, como exemplo, os pais que participavam de encontros reflexivos na creche da comunidade, que, apesar de se queixarem em todo encontro reflexivo da dificuldade na relação com os filhos e do sofrimento relativo a tais dificuldades, não conseguiam se posicionar diante deles de outro modo. Ou ainda, no caso de uma cooperativa formada por mulheres da comunidade que participavam de encontros reflexivos a respeito das experiências nela vividas, em que o impasse vivido entre assumirem a cooperativa de um modo mais autônomo ou permanecerem agindo do mesmo modo, amplamente dialogado nos encontros reflexivos, só foi transposto com o fechamento da organização.

Além disso, outra questão importante é que nas práticas em que ações no sentido da saída da mesmidade se mostraram presentes - que foi na maioria dos casos analisados -, havia outras questões em jogo para além da reflexão. Tais percepções formaram a constelação da qual trataremos a seguir: "os limites da reflexão".

Antes da explanação a respeito dessa constelação, abriremos um parêntese para as pontuações teóricas, buscando retomar as reflexões de Arendt (2001a) sobre o pensamento como uma das atividades constituintes do homem. Segundo a autora, a vida é dada ao homem a partir de determinadas condições. São elas: a Terra, a vida biológica, a mundanidade, a pluralidade, a natalidade, a mortalidade e o próprio condicionamento.

A Terra refere-se ao habitat no qual o homem vem ao mundo. A vida biológica diz respeito à manutenção da vida, à ocupação com a sobrevivência. A mundanidade refere-se à necessidade do homem em criar artefatos 
para poder habitar o mundo, tornando-o menos inóspito do que o mundo natural. A pluralidade diz respeito ao fato de que, como lembra Arendt (2002, p. 17), "não o Homem, mas os homens habitam o mundo", remetendo à condição humana de singularidade/pluralidade. A natalidade evidencia não só o fato do nascimento biológico do homem, mas também o caráter iniciador do homem, no curso do mundo e/ou em sua própria biografia. A mortalidade está vinculada ao tempo, à permanência do homem no mundo, à história. E, por último, a condição de o homem nascer sob certas condições, ou seja, o próprio condicionamento (Arendt, 2001a).

O homem nasce nessas condições e a partir delas se constitui. É importante assinalar que o fato de o homem ser condicionado não possui nenhum traço determinista, apenas revela sua origem, o lugar de onde parte. Ao longo do processo de constituição, as pessoas se relacionam com o que se apresenta a elas a partir de uma série de atividades. Hannah Arendt divide essas atividades humanas em Vida Ativa e Vida Contemplativa, ou Vida do Espírito.

A Vida Ativa é constituída pelas atividades do Labor, do Trabalho e da Ação. Já a Vida do Espírito, ou Contemplativa, compreende as atividades do Pensar, do Querer e do Julgar (Arendt, 2001a). Tendo isso em vista, podemos começar a mencionar em que consistem as atividades da Vida Ativa: o Labor, o Trabalho e a Ação.

O Labor se encarrega da manutenção da vida biológica, da satisfação das necessidades vitais e, em última instância, da sobrevivência da espécie. Assim, ele está vinculado à condição da vida biológica e, de alguma maneira, à natalidade e à mortalidade - natalidade e mortalidade em seu caráter biológico, tanto do indivíduo como da espécie. Uma das características mais marcantes do Labor é que ele é incessante, visto que, na medida em que o cuidado com o bem-estar físico se encerra, já há, em seguida, novas necessidades de alimentação, higiene, abrigo, entre outros, evocando atenção (Arendt, 2001a).

O Trabalho é a atividade que cria artefatos para que o homem possa habitar a Terra, criando um mundo artificial duradouro, para que este não seja tão inóspito a ele quanto o é o ambiente natural. É essa atividade que cuida da condição humana de mundanidade e da habitação na Terra, e, por meio da criação desse mundo artificial e duradouro, também se vincula a questão da natalidade e mortalidade, emprestando "[...] permanência e durabilidade à futilidade da vida mortal e ao caráter efêmero do tempo humano" (Arendt, 2001a, p. 16).

A Ação está vinculada à questão da condição humana de pluralidade, ao fato de o homem ser sempre entre homens. Como observa Arendt (2001a, p. 15), "[...] o idioma romano [...] empregava como sinônimas as expressões 'viver' e 'estar entre os homens' (inter homines esse). Ou 'morrer' e 'deixar de estar entre os homens' (inter homines esse desinere)".

Arendt lembra que a pluralidade se refere também ao fato de o homem ser igual a todos os homens e, ao mesmo tempo, ser distinto, singular. Assim, por meio de cada nascimento, vem ao mundo um homem igual 
a todos os outros e, ao mesmo tempo, singular, único. Essa singularidade sempre traz ao mundo uma novidade e a possibilidade de inovação por meio da distinção. Entretanto, essa distinção só se manifesta na presença de outros; é preciso que outros a percebam e a qualifiquem como tal, lembrando que "Nada nem ninguém existe neste mundo cujo próprio ser não pressuponha um espectador. [...] Ser e Aparecer coincidem" (Arendt, 2002, p. 17).

Essa explicitação da singularidade, demarcando a distinção, só poderá aparecer por meio da Ação. É por meio de atos e palavras que os homens se apresentam ao mundo humano, e "[...] esta inserção é como um segundo nascimento, no qual confirmamos e assumimos o fato original e singular do nosso aparecimento físico original" (Arendt, 2001a, p. 190).

É importante chamar a atenção para o fato de que este não é qualquer ato, mas um ato compreendido como algo distinto do que se apresentava até então, capaz de iniciar um novo movimento. Por essa razão, a Ação é, também, a atividade humana vinculada à natalidade, mas a natalidade não em seu sentido biológico, mas com o fato de "o" homem em sua biografia e "os" homens na história do mundo possuírem esse poder de dar início a um novo movimento, que rompe com a linearidade, com a mesmice.

Assim, a pessoa que inicia a Ação inicia pelo fato de, por meio de atos e palavras, expor sua singularidade diante de outros, e, ao fazê-lo, distingue-se trazendo o inesperado. No entanto, esse inesperado compartilhado atinge não só quem o trouxe, mas os que foram testemunhas de sua aparição. Segundo Arendt (2001a, p. 203), "Como a ação atua sobre seres que também são capazes de agir, a reação, além de ser uma resposta, é sempre uma nova ação com poder próprio de atingir e afetar os outros".

Desse modo, a Ação tem caminhos imprevisíveis, pois ela surge sempre em meio a uma "teia de relações" e por ela é "acabada". O produto da Ação não tem um autor determinado, é, por isso, inesperado (e também irreversível, visto que o que se fez não se pode apagar). Como observa Arendt (2001a, p. 197), "[...] as histórias, resultado da ação e do discurso, revelam um agente, mas esse agente não é autor nem produtor. Alguém a iniciou e dela é o sujeito, na dupla acepção da palavra, mas ninguém é seu autor".

Como se pode observar, a Ação está vinculada à política no sentido de ter nela o seu fundamento. A esse respeito, Arendt assinala que essa é a única atividade que não pode ser feita na solidão. O Labor e o Trabalho são atividades que podem ser realizadas no isolamento, já a Ação necessita ser feita entre os homens.

Ao contrário da Vida Ativa, a Vida Contemplativa ou Vida do Espírito não tem na lida direta com o mundo seu campo de atuação. É justamente a retirada do mundo, o alheamento, uma das características principais das atividades que compõem a Vida do Espírito: o Pensar, o Querer e o Julgar (Arendt, 2002, p. 63). Esse alheamento das coisas do mundo, característica própria da atividade do espírito, não acontece da mesma forma em todas as atividades. Esse é um dado importante que merece ser mais bem detalhado. 
$\mathrm{Na}$ experiência do pensamento, como foi mencionado, podemos especular sobre uma infinidade de possibilidades, ampliar compreensões, rever posicionamentos. Para isso, o pensamento trabalha com coisas-pensamento, trazendo para o presente objetos ausentes por meio da imaginação. Segundo Arendt (2001b, p. 252), a imaginação

[...] nos torna capazes de ver as coisas segundo a sua perspectiva própria, de sermos suficientemente fortes para pormos aquilo que está demasiado perto a certa distância, de maneira a podermos vê-lo sem distorções nem preconceitos, de sermos generosos quanto baste para transpormos os abismos da separação até podermos ver e compreender as coisas que se encontram demasiado longe de nós como se fossem caso nosso.

Assim, em uma "lacuna entre o passado e o futuro" (Arendt, 2002, p. 158), o pensamento pode, com certo conforto, refletir sobre o que passou e levantar especulações acerca do futuro, por meio da imaginação. Assim, não há no momento de realização do pensamento exigências de uma volta imediata para a realidade. No caso do pensamento filosófico isso fica explícito. Entretanto, ainda que tenha sido uma urgência em voltar à vida que impulsionou o ato de pensar, como no caso da compreensão; quando está em atividade, a compreensão é quietude, no sentido de contemplação.

Outro dado importante acerca do pensamento é que, quer seja como pensamento filosófico ou como compreensão, a reflexão não lida com a resistência apresentada pela realidade, pois as coisas-pensamento não possuem a textura da qual a realidade é constituída.

Já a Vontade, apesar de ser uma atividade do espírito, tendo como princípio para que ocorra o abandono da realidade, anseia em se realizar, em voltar para a realidade e se expressar por meio da ação.

Essa diferença de disposição entre Pensamento e Vontade aparece de vários modos; um deles diz respeito ao fenômeno de duplicação que ocorre durante a realização de todas as atividades do espírito, explicitado por Arendt (2002, p. 137) da seguinte forma:

Chamamos de consciência (literalmente, "conhecer comigo mesmo" [...]) o fato curioso de que, em certo sentido, eu também sou para mim mesmo, embora quase não apareça para mim [...]; eu não sou apenas para os outros, mas também para mim mesmo; e, nesse último caso, claramente eu não sou apenas um. Uma diferença se instala na minha Unicidade.

Desse modo, a autora demarca que, apesar do alheamento do mundo e do distanciamento dos outros, a pluralidade se mantém nas atividades do espírito, sendo o homem essencialmente no plural (Arendt, 2002). Ou seja, mesmo quando não está entre homens, mesmo quando está a sós consigo mesmo, há um outro (si mesmo) presente.

No caso específico do pensamento, Arendt compara a dualidade do eu comigo mesmo com o diálogo com um amigo, e, podemos dizer que, como todo diálogo com um amigo, esse pode ser estendido por longos períodos. 
Tratando-se da Vontade, ocorre o contrário, há um embate entre o dois-em-um, pois, sempre quando se apresenta um querer, automaticamente apresenta-se também o seu oposto, o não-querer. Esse conflito só será resolvido na ação. "Em outras palavras, a Vontade é redimida, cessando de querer e começando a agir, e a interrupção não pode se originar de um ato de querer-não-querer, pois isso já seria uma nova volição" (2002, p. 261).

Além disso, imediatamente a um querer se apresentam também o medo e a esperança de que esse querer se realize ou não, trazidos à tona não só pelo quero e não quero, como também pelo quero e posso/ não posso. Novamente aqui a Vontade aparece como conflito e não como diálogo e quietude, como no caso do pensamento. Como lembra Arendt (2002, p. 214), a Vontade

[...] anseia por seu próprio fim, o momento em que o querer algo terá se transformado em fazê-lo. Em outras palavras, o humor habitual do ego volutivo é a impaciência, a inquietude e a preocupação (Sorge), não somente porque a alma reage ao futuro com esperança e medo, mas também porque o projeto da vontade pressupõe um "eu-posso" que não está absolutamente garantido. A inquietação da vontade só pode ser apaziguada com um "eu-quero-e-faço".

Como projeção para o futuro, o querer se apresenta como o "querer o próprio eu". Arendt retoma Heidegger para expressar essa ideia. Ainda segundo a autora,

A auto-observação e o autoexame nunca trazem à luz o eu ou mostram como nós mesmos somos. Mas, ao querer e também ao não-querer, fazemos exatamente isso; aparecemos em uma luz que é em si iluminada por um ato de vontade (Arendt, 2001a, p. 318).

É justamente no fato de ser uma atividade projetada para o futuro que reside o caráter inovador e poderoso da Vontade. É nele que a Vontade estabelece seu vínculo estreito com a liberdade e com sua explicitação por meio da Ação. É por meio do lançar-se para um futuro incerto e querer realizar um eu, independentemente das configurações anteriores, o que faz da "vontade a fonte da ação". É por meio da Vontade que se abre a possibilidade da iniciação de algo novo.

Isso porque é próprio do pensamento partir sempre do que passou, "pensar é sempre re-pensar", não conseguindo assim descolar-se da realidade para propor algo novo que seja capaz de ser "indiferente" ao passado e à realidade, para que, "indiferente" às possibilidades restritivas anteriores, se lance para o futuro. Conforme a autora, a atividade capaz de tal atrevimento diante da história e do presente é a Vontade. "A vontade, ao que parece, tem uma liberdade infinitamente maior do que o pensamento, que mesmo em sua forma mais livre, mais especulativa, não pode escapar ao princípio da não contradição" (Arendt, 2002, p. 190). Absolutamente dirigida para o futuro, a Vontade direciona para ele suas ambições, desvencilhando-o desse modo de suas determinações. 
Assim, o querer está associado à identidade, ao eu que quer se realizar no futuro, independentemente da história. Esse poder, porém, de abertura da Vontade só aparece diante de uma crença em poder se realizar. Ou seja, o eu que quer também aparece como aquele que pode ou não realizar esse querer. Retomando a citação feita anteriormente, foi mencionado que "o projeto da vontade pressupõe um 'eu-posso'" (Arendt, 2002, p. 214). Ou seja: "[...] o fato de a vontade ser livre e de não ser determinada ou limitada por qualquer objeto dado, exterior ou interiormente, não significa que o homem como homem goze de liberdade ilimitada" (Arendt, 2002, p. 291).

Arendt (2000, p. 208) lembra ainda que "[...] Somente quando o quero e o posso coincidem a liberdade se consuma". Assim, a questão do poder é fundamental para que a Vontade se dirija para a Ação. Isso porque "O poder da vontade reside em sua decisão soberana de interessar-se somente pelas coisas que estão em poder do homem; [...] Logo, a primeira decisão da Vontade é não querer o que não pode obter" (Arendt, 2002, p. 244).

Nesse sentido, tendo em vista que a Vontade é compreendida por Arendt (2002, p. 260) como "a fonte da ação" e que o querer se realizar implica a confiança desse poder, a falta de Ação pode estar vinculada à falta de poder, segundo a leitura realizada por Arendt (2002) sobre Santo Agostinho. A Vontade está, portanto, inteiramente vinculada à questão da liberdade e esta vinculada à questão do poder.

Assim como a Vontade, o Juízo, a "habilidade de distinguir o certo do errado, o belo do feio", também se apresenta como uma atividade do espírito que, apesar da retirada do mundo, tem pressa de voltar a ele. Segundo Arendt (2002), a faculdade de julgar particulares (tal como foi revelada em Kant), a habilidade de dizer "isso é errado", "isto é belo", e por aí afora, não é igual à faculdade de pensar. O pensamento lida com coisas invisíveis, com representações de coisas que estão ausentes. Já o Juízo "[...] sempre se ocupa com particulares e coisas que estão ao alcance das mãos. [...] E isso, nos raros momentos em que as cartas estão postas sobre a mesa, pode sem dúvida prevenir catástrofes, ao menos para o eu" (Arendt, 2002, p. 145). Como a compreensão, o Juízo também se retira para assistir ao jogo da vida, mas, nesse caso, com o intuito de se afastar para julgá-la, ocupado com a questão da ética e, portanto, com a política.

Assim, após essas observações, podemos dizer que, ao olhar para a atividade do espírito, temos diante de nós três atividades autônomas. Segundo a autora, é fato que é o pensamento quem dessensorializa os objetos, constituindo as coisas-pensamento, trazendo-as por meio da imaginação. Essas serão utilizadas tanto pelo pensamento como pela Vontade e pelo Juízo.

Desse modo, o pensamento prepara o objeto para as demais atividades do espírito, mas essas não são modos diferentes de o pensamento se apresentar nem são governadas por ele. Além disso, podemos constatar que, das três atividades, aquela que se distancia mais radicalmente do jogo da vida é justamente o pensamento. 
Recorrendo a Arendt (2002, p. 71), novamente:

Estive falando sobre as características especiais do pensamento que podem ser atribuídas ao radicalismo de sua retirada do mundo. Em contrapartida, nem a vontade, nem o juízo, embora dependentes da reflexão preliminar que o pensamento faz sobre os objetos, ficam presos a essa reflexão; seus objetos são particulares [...], têm seu lar estabelecido no mundo das aparências, do qual o espírito volitivo ou judificante se retira apenas temporariamente e com a intenção de uma volta posterior.

No entanto, ao longo da história dificilmente houve a compreensão da autonomia dessas atividades do espírito. De modo geral, elas foram pensadas como derivadas do pensamento. Além disso, o pensamento era visto como hierarquicamente superior às demais atividades do espírito, tendo-as sob seu comando.

E, ainda, o pensamento comandaria não só a Vida Contemplativa, mas também a Vida Ativa. Tal fato se pauta na crença de que a Vida Ativa seria hierarquicamente inferior à Vida Contemplativa (Arendt, 2001, p. 24).

O esboço das reflexões de Arendt a respeito das atividades humanas desvela a importância dessas para a vida humana, não reconhecendo assim uma escala hierárquica entre elas. No que se refere ao pensar, a autora lembra que isso não significa

[...] contestar ou até mesmo discutir o conceito tradicional de verdade como revelação e, portanto, como algo essencialmente dado ao homem, ou que prefira a asserção pragmática da era moderna de que o homem só pode conhecer o que ele mesmo faz. [O] uso que dou à expressão vita activa pressupõe que a preocupação subjacente a todas as atividades não é a mesma preocupação da vida contemplativa, como não lhe é superior nem inferior (Arendt, 2001, p. 26).

Retomaremos agora a segunda constelação da qual tratávamos antes deste parêntese para pontuações teóricas: "os limites da reflexão". As práticas abordadas nessa constelação evidenciaram um estreito vínculo entre o fenômeno da Ação e a reflexão como compreensão. Essa, como vimos, acompanha todo o processo da Ação, é sua "outra face" (Arendt, 2001b, p. 251), permite o retorno ao mundo. No entanto, em meio a todos os relatos apresentados, há demonstrações de que existem sempre várias peças no jogo. Algumas, como no caso da Vontade e do Juízo, diretamente vinculadas ao comando das ações, ou à sua paralisação.

Outras apareceram como propulsoras de novos movimentos, como no caso do poder e da pluralidade. Desse modo, podemos perceber que o poder da compreensão, apesar de fundamental, é também limitado. Limitado pela sua própria natureza como atividade do espírito e limitado pelo espaço ocupado pelas demais peças envolvidas no jogo. Sem dúvida, temos na reflexão a matéria prima para o trabalho em psicologia da educação. Entretanto, é importante que estejamos abertos e sensíveis às outras questões que aparecem, lembrando que o homem é aquele que compreende, que quer, que julga, que age, que trabalha, que cuida da 
sobrevivência, enfim, que está esparramado em todas essas atividades e cercado de determinadas condições.

Não há aqui, de forma alguma, uma desqualificação da reflexão, apenas a preocupação em não colocá-la em um papel onipotente ou, até mesmo, determinista. Tal postura pode propiciar que possamos trilhar caminhos mais criativos diante da exigência de cada caso sobre o qual nos inclinamos. Entre os vários aspectos que envolvem as intervenções realizadas está "a questão da condição". Dissemos anteriormente que o homem nasce sob certas condições e que se constitui a partir dela. É importante ressaltar que tais condições demarcam apenas sua origem, mas de modo algum o determina. Como assinala Arendt (2001a, p. 19):

[...] as condições da existência humana - a própria vida, a natalidade e a mortalidade, a mundanidade, a pluralidade e o planeta Terra - jamais podem "explicar" o que somos ou responder a perguntas sobre o que somos, pela simples razão de que jamais nos condicionam de modo absoluto.

Isso porque:

Além das condições nas quais a vida é dada ao homem na Terra e, até certo ponto, a partir delas, os homens constantemente criam as suas próprias condições que, a despeito de sua variabilidade e sua origem humana, possuem a mesma força condicionante das coisas naturais (Arendt, 2001a, p. 18).

Trouxemos anteriormente a questão do condicionamento com o intuito de tratar do contexto no qual vivem as pessoas que participam das intervenções realizadas. Logo, é importante compreendê-lo não como um fator determinante, mas um lugar (entre outros tantos) do qual partem as ações ou as paralisações que testemunhamos em nossas intervenções.

As práticas relatadas descrevem que a vulnerabilidade é um fato constantemente observado na comunidade pesquisada. Trata-se de uma população de fato desprotegida, no sentido da falta de serviços essenciais que deveriam ser dados pelo Estado e, ao mesmo tempo, falta de poder econômico para que seus membros possam se proteger satisfatoriamente sozinhos. Assim, por exemplo, como não existem vagas suficientes na creche, é comum que crianças muito pequenas fiquem em lugares inapropriados enquanto suas mães trabalham fora. Tal fato tem íntima relação com o grande número de relatos de abusos sexuais nas intervenções realizadas, o que levou a direcionar os temas de trabalho, realizado nos encontros com os pais e mães, para modos de proteção possíveis nessa situação.

Outro exemplo dessa fragilidade refere-se ao impacto da violência criminal na vida das pessoas da comunidade que, de modo geral, ao serem por ela atingidos, não veem formas possíveis de lidar com a situação devido ao medo e à servidão. A violência extrema está presente na grande maioria das pesquisas consultadas. Quase todas têm relatos de assassinatos ou proximidade com o crime, mas, para além dessa, explicitam também uma 
forma violenta de o mundo tratá-las. A esse respeito, a luta conjunta, além de revelar a possibilidade de enfrentamento de situações absurdamente adversas, também garante realidade ao poder de realização de ações em nome da Vontade de melhorias da comunidade.

É possível verificar que as pessoas que fazem parte da vida pública da comunidade, participando de alguma forma da associação de moradores ou do gerenciamento da creche, por exemplo, têm um poder de realização importante tanto para si, de modo particular, como para a comunidade. Parece haver uma forte ligação entre o querer e o poder realizar e a participação na vida pública da comunidade e entre o querer e o não poder realizar e a solidão da vida privada. É claro que essas indicações não são prescritivas, e encontramos vários exemplos em que a própria associação comunitária não conseguiu empenhar-se em seus quereres; no entanto, o poder é, ainda assim, mais presente nesses espaços. Podemos perceber também que a crença do poder de realização das pessoas se enfraquece diante de questões como a violência que permeia a comunidade ou os maus-tratos constantes sofridos nos hospitais, transportes públicos e escolas frequentados.

Ao final dessa constelação, podemos indicar sobre a relação entre poder e o contexto da comunidade: o contexto pode contribuir para um sentimento de falta de poder e para a falta de poder efetivamente para realizar ações; além disso, a participação na vida pública manifesta-se como intimamente vinculada à revelação de poder realizar volições, ao contrário do isolamento na vida privada.

\section{Considerações finais}

Finalmente, trataremos da última constelação constituída ao longo das leituras: "apontamentos para novas possibilidades de trabalho". Esta será utilizada neste artigo como "considerações finais", pois indica o sentido das exposições feitas até o presente momento.

O primeiro e mais importante apontamento desvelado na pesquisa abordada por este artigo diz respeito à necessidade de uma relativização da reflexão concernente ao fim último das intervenções realizadas na comunidade, qual seja a ação, a iniciação de um novo movimento.

A pesquisa nos convidou para um descongelamento da crença na reflexão como peça decisiva para impulsionar ações e para a explicitação de que "[...] o ego pensante não é o eu". O eu é aquele que quer, que pensa, que julga, que trabalha, que labora e que age, não podendo assim o processo identitário estar "ancorado no pensamento" (Arendt, 2002, p. 34).

Há vários aspectos vinculados à questão da Ação, para além da reflexão. A compreensão está presente, assim como a Vontade, o Juízo, o Poder, a Pluralidade, os condicionamentos, entre outros. Diante de tais questões, devemos estar atentos ao cuidado com essas diversas demandas trazidas pelo fenômeno da Ação.

Os trabalhos que estão sendo realizados pelo grupo Ecofam, no momento, caminham no sentido desse cuidado. O esforço de nosso 
trabalho direciona-se agora para que nós compreendamos que exigências o caso nos faz e para onde temos que nos voltar, não sendo necessariamente para a reflexão.

\section{Referências bibliográficas}

ANDRADE, Ângela Nobre de; MORATO, Henriette Tognetti Penha. Para uma dimensão ética da prática psicológica em instituições. Estudos de Psicologia, v. 9, n. 2, p. 345-353, 2004. Disponível em:

$<$ http://www.scielo.br/pdf/epsic/v9n2/a17v9n2.pdf>.

ARENDT, Hannah. Entre o passado e o futuro. São Paulo: Perspectiva, 2000 .

. A condição humana. Rio de Janeiro: Forense Universitária, 2001a.

Compreensão e política e outros ensaios. Lisboa: Relógio D’Água Editores, 2001b.

. A vida do espírito: o pensar, o querer, o julgar. 5. ed. Rio de Janeiro: Relume Dumará, 2002.

CALIL, Simone Dalla Barba Walckoff. A experiência de mulheres de uma comunidade de baixa renda em uma cooperativa de costura e suas implicações com o processo identitário. 2004. Dissertação (Mestrado em Psicologia da Educação) - Pontifícia Universidade Católica de São Paulo (PUC-SP), 2004.

. A questão da reflexão e da ação nas práticas psicoeducativas na pesquisa interventiva. 2009. Tese (Doutorado em Educação Psicologia da Educação) - Pontifícia Universidade Católica de São Paulo (PUC-SP), São Paulo, 2009. Disponível em: < http://www. dominiopublico.gov.br/pesquisa/DetalheObraForm.do?select_ action $=\&$ co_obra $=143875>$.

CAMASMIE, Ana Tereza. Narrativas de histórias pessoais: um caminho de compreensão de si mesmo à luz do pensamento de Hannah Arendt. 2007. Dissertação (Mestrado em Filosofia) - Pontifícia Universidade Católica de São Paulo (PUC-SP), São Paulo, 2007. Disponível em: $<$ http://www.dominiopublico.gov.br/pesquisa/DetalheObraForm. do?select_action $=\&$ co_obra $=78212>$.

CUNHA, Antonio Geraldo. Dicionário etimológico da língua portuguesa. Rio de Janeiro: Lexikon, 1986. 
CUNHA, Dênio. Tempo de ensinar e tempo de aprender: a temporalidade e professores de uma Escola Pública. 2005. Dissertação (Mestrado em Educação) - Pontifícia Universidade Católica de São Paulo (PUC-SP), São Paulo, 2005.

ECOFAM. Relatório dos encontros de pais realizados em 2004-2005. São Paulo: PUC, 2004.

FREIRE, Paulo. Pedagogia do oprimido. São Paulo: Paz e Terra, 2003.

FUSER, Carlos. Os sentidos das atividades realizadas pelos alunos nas aulas de Arte: um estudo fenomenológico em uma escola da periferia de São Paulo. 2005. Dissertação (Mestrado em Psicologia da Educação) - Pontifícia Universidade Católica de São Paulo (PUC-SP), São Paulo, 2005.

\section{GRUPO DE PESQUISA EM PRÁTICAS EDUCATIVAS E ATENÇÃO} PSICOEDUCACIONAL À FAMÍLIA, ESCOLA E COMUNIDADE ver Ecofam.

HERMANN, N. Hermenêutica e educação. Rio de Janeiro: DP\&A, 2002.

MELO, Fabíola Freire. Plantão psicoeducativo: espaço de reflexão e mudança oferecido às famílias de uma comunidade de baixa renda. 2004. Dissertação (Mestrado em Psicologia da Educação) - Pontifícia Universidade Católica de São Paulo (PUC-SP), São Paulo, 2004.

SANCHES, Regina Suini. Plantão psicoeducativo para jovens em uma periferia da cidade de São Paulo: uma experiência provocadora de uma reflexão sobre práticas educativas. 2006. Dissertação (Mestrado em Psicologia da Educação) - Pontifícia Universidade Católica de São Paulo (PUC-SP), São Paulo, 2006. Disponível em: < http://www.bdae.org.br/ dspace/bitstream/123456789/1877/1/tese.pdf>.

SZYMANSKI, H. A prática reflexiva em pesquisa com famílias de baixa renda. 2004. Trabalho apresentado no II Seminário de Pesquisas e Estudos Qualitativos (SEPQ), Bauru, São Paulo, 2004a.

Plantão psicoeducativo: novas perspectivas para a prática e pesquisa em psicologia da educação. Psicologia da Educação, São Paulo, v. 19, n. 2, p. 169-182, 2004b. Disponível em: <http://pepsic.bvsalud. org/scielo.php?pid=S1414-69752004000200009\&script=sci_arttext $>$.

SZYMANSKI, H.; CURY, Vera Engler. A pesquisa intervenção em psicologia da educação e clínica: pesquisa e prática psicológica. Estudos de Psicologia, Natal, v. 9, n. 2, p. 355-364, maio/agosto. 2004. Disponível em: <http://www.scielo.br/scielo.php?pid=S141394X2004000200018\&script=sci_arttext $>$. 
SZYMANSKI, H. (Org.). A entrevista na pesquisa em educação: a prática reflexiva. Brasília: Plano, 2002.

TINTI, Rafael Ogalla. "Morreu com as mãos sujas de graxa": um olhar fenomenológico-existencial para a morte na prática do plantão psicoeducativo. 2006. Dissertação (Mestrado em Psicologia da Educação) - Pontifícia Universidade Católica de São Paulo (PUC-SP), São Paulo, 2006.

VIANNA, Fernanda Camargo. Histórias da periferia: a maconha no mundo de jovens estudantes de uma escola pública de São Paulo - uma análise fenomenológica. 2006. Dissertação (Mestrado em Psicologia da Educação) - Pontifícia Universidade Católica de São Paulo (PUCSP), São Paulo, 2006. Disponível em: < http://www.bdae.org.br/dspace/ bitstream/123456789/1877/1/tese.pdf>

Simone Dalla Barba Walckoff, doutora em Psicologia da Educação pela Pontíficia Universidade Católica de São Paulo (PUC-SP), é professora do curso de Práticas Psicoeducativas em Instituições e Comunidades no Cogeae-SP e de Temas em Psicologia Social e Psicologia Institucional na Universidade Paulista - Unip-Pinheiros.

psicoclinica@gmail.com

Heloisa Szymanski, doutora em Psicologia da Educação pela Pontifícia Universidade Católica de São Paulo (PUC-SP), é professora titular dessa instituição.

psicoclinica@gmail.com

Recebido em $1^{\circ}$ de setembro de 2011.

Aprovado em 18 de abril de 2012. 